\title{
Physicochemical Properties of Sb-Sn-Zn Alloys
}

\author{
TOMASZ GANCARZ ${ }^{1,2,3}$ \\ 1.-Institute of Metallurgy and Materials Science, Polish Academy of Sciences, Kraków, Poland. \\ 2.—e-mail: nmgancar@imim-pan.krakow.pl.3.—e-mail: tomasz.gancarz@imim.pl
}

In this work, liquid Sb-Sn-Zn alloys were studied to determine their density, viscosity, and surface tension using the discharge crucible method. The measurements were carried out for alloy compositions having $X_{\mathrm{Sn}} / X_{\mathrm{Sb}}$ ratio of $1,3,4$, and 9 and $\mathrm{Zn}$ content $X_{\mathrm{Zn}}$ of $0.05,0.1,0.2$, and 0.7 in the temperature range from $550 \mathrm{~K}$ to $1050 \mathrm{~K}$. The effect of the $\mathrm{Zn}$ concentration in the Sb-SnZn alloys on their density, viscosity, and surface tension was observed. Over a wide temperature range, the viscosity and surface tension increased with increasing $\mathrm{Zn}$ content in the alloy, while the density decreased. The experimental results obtained for surface tension and viscosity were compared with the results of the Butler model for surface tension and with the MoelwynHughes, Sichen-Boygen-Seetharaman, Seetharaman-Sichen, Kozlov-Romanov-Petrov, and Kaptay models for viscosity.

Key words: Discharge crucible method, Sb-Sn-Zn alloys, density, surface tension, viscosity

\section{INTRODUCTION}

The introduction of an European Union Directive and the explorative work on lead solder replacements resulted in interest in $\mathrm{Sb}-\mathrm{Sn}-\mathrm{Zn}$ alloys, which are potential replacements for lead solder. The most popular alloys can be divided into two main groups, i.e., Sn-Ag-Cu (SAC) and Sn-Zn, which are used as replacements for low-temperature lead-based solders (Sn-Pb, Sn-Pb-Cd). ${ }^{1}$ Further applications of $\mathrm{Sb}-\mathrm{Sn}$-Zn alloys are as a sputtered amorphous layer of compact discs (CDs) for storing information ${ }^{2}$ and as a solid-state phase in $\mathrm{Zn}_{4} \mathrm{Sb}_{3^{-}}$and $\mathrm{SnZnSb}_{2^{-}}$ modified InSb, ${ }^{3}$ resulting in further interest in this system. The main trend of research is to find replacements for lead solder with low- and hightemperature properties similar to those of toxic

(Received March 5, 2014; accepted July 5, 2014;

published online September 9, 2014) solders containing $\mathrm{Pb}$ and $\mathrm{Cd}$, which are characterized by melting points above $473 \mathrm{~K}$ and $623 \mathrm{~K}$, respectively, for use in different types of connections, not only as solder alloys for pressure soldering, but also for installation of optical components in industries such as automotive, aerospace, electronics, etc. ${ }^{4}$

Eutectic Sn-Zn alloys ${ }^{5-8}$ form the second most interesting group of metallic materials for use in the electronics industry, the first being the triple eutectic Ag-Sn-Cu (SAC) alloys. ${ }^{9-11}$ The most frequently used solder modifiers for Sn-Zn eutectic are bismuth, indium, and antimony. ${ }^{12-14}$ Antimony addition is used to improve the mechanical properties and increase the melting temperature range from $472 \mathrm{~K}$ to $500 \mathrm{~K}{ }^{15}$ Addition of antimony to SAC with composition $\mathrm{Sn}-3.5 \mathrm{Ag}-0.7 \mathrm{Cu}$ (at.\%) increases its tensile strength, ${ }^{16}$ with the best results observed for 1 at.\% $\mathrm{Sb}$ content. Addition of $\mathrm{Sb}$ to eutectic Sn-3.5Ag alloy increases the melting point of the ternary Sn-Ag-Sb alloy ${ }^{17}$ and changes the structure of the starting Sn-Ag alloy, with increasing hardness for increasing antimony concentration. In wetting tests, higher $\mathrm{Sb}$ content in $\mathrm{Sb}-\mathrm{Sn}$ alloys resulted in decreases of intermetallic layers. ${ }^{18}$ Increases of the melting point and decreases of the density and surface tension with increasing $\mathrm{Sb}$ 
content have been observed in ternary Sn-Ag-Sb alloys. ${ }^{19}$ Addition of antimony was also observed to improve the mechanical properties of $\mathrm{Sn}-\mathrm{Ag}$ alloy, with 1.5 at.\% Sb content being particularly suitable. According to Miric's ${ }^{20}$ study, the poor wettability of $\mathrm{Sn}-25 \mathrm{Ag}-10 \mathrm{Sb}$ (at.\%) alloy on $\mathrm{Cu}$ substrate corresponds to the high content of antimony, in contrast to the data obtained in Ref. 19 for $\mathrm{Sn}-\mathrm{Ag}$-Sb with $\mathrm{Sb}$ content from 8 to 20 , for which the contact angle on $\mathrm{Cu}$ was almost the same $\left(\sim 33^{\circ}\right)$.

The lack of experimental data on the physicochemical properties of $\mathrm{Sb}-\mathrm{Sn}-\mathrm{Zn}$ alloys prevents their potential use in a wide range of applications. The only data for this system is the projection of the liquidus surface, ${ }^{21}$ which was prepared on the basis of data from binary systems without taking into account the impact of ternary data, which were unavailable at that time (1976). The thermodynamic equilibrium relations for liquid Sb-Sn-Zn alloys were described in Ref. 22 .

The aim of this work is to analyze new experimental data for the density, surface tension, and viscosity of liquid $\mathrm{Sb}-\mathrm{Sn}-\mathrm{Zn}$ alloys in view of different models.

\section{EXPERIMENTAL PROCEDURES}

\section{Sample Preparation}

The alloys were prepared from pure $\mathrm{Sb}, \mathrm{Sn}$, and Zn (all of purity $99.999 \%$ ) according to the nominal compositions by the Institute of Electronic Materials Technology and the Experimental Department at Skawina Ironworks. The samples were prepared
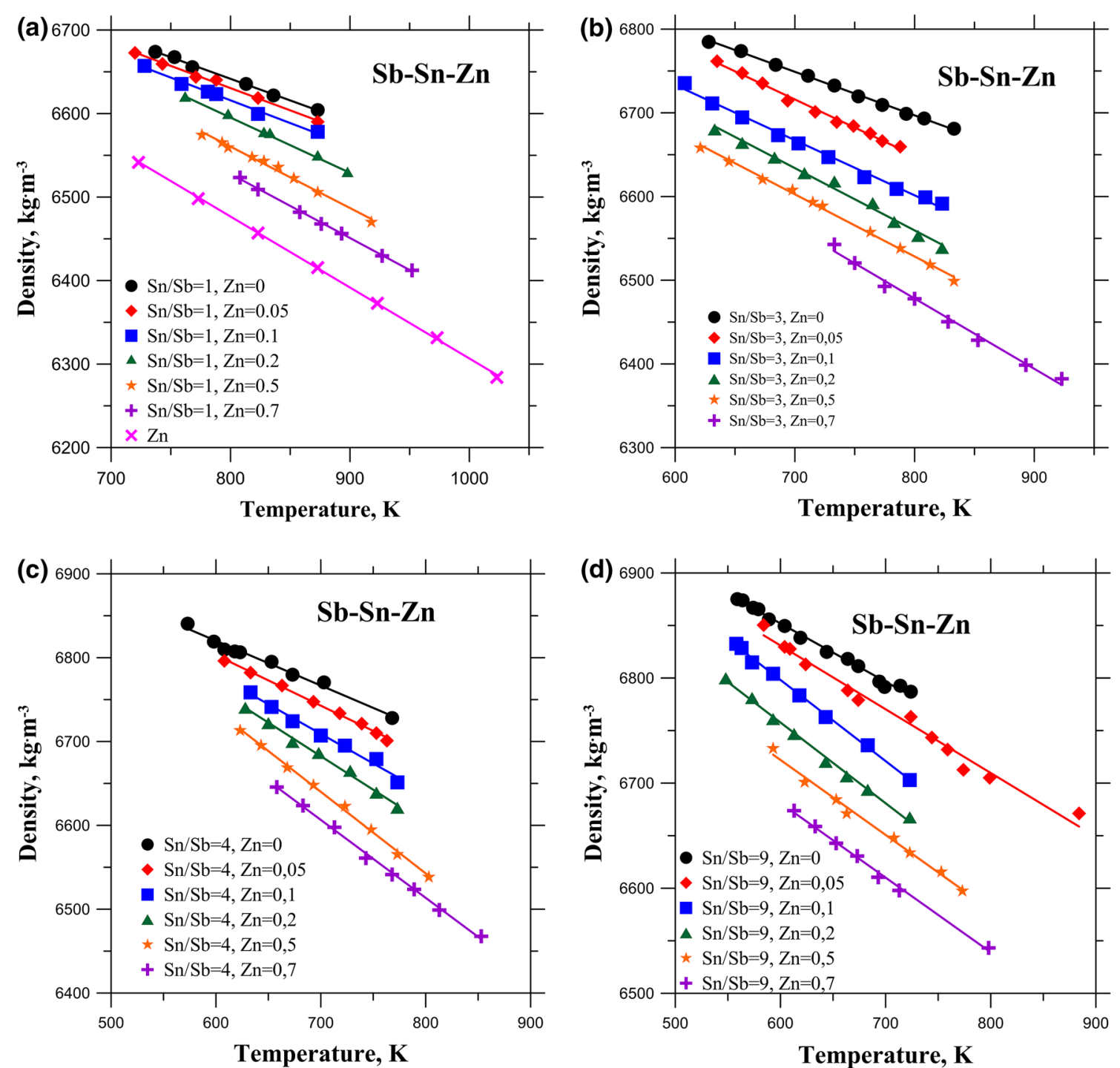

Fig. 1. Density of Sb-Sn-Zn alloys for constant $X_{\mathrm{Sn}} / X_{\mathrm{Sb}}$ ratio of (a) 1, (b) 3, (c) 4, and (d) 9 with Zn addition. 
using an electronic balance to accuracy of $0.1 \mathrm{~g}$ with total weight of approximately $1.5 \mathrm{~kg}$. Then, samples were melted in a graphite measuring crucible. The experiment began when the temperature stabilized. For measurements of surface tension, density, and viscosity, the discharge crucible (DC) method was used. ${ }^{23,24}$ The study was conducted in a glovebox under a protective atmosphere of $99.9999 \%$ pure argon, where the volume concentration of $\mathrm{O}_{2}$ and $\mathrm{H}_{2} \mathrm{O}$ was less than $1 \mathrm{ppm}$. The atmosphere provided by this equipment ensures that the tests were carried out under stable and repeatable conditions. This method allows one to obtain these three properties from one test at a given temperature. The molar volume was calculated from the experimental density. For the isotherms at $923 \mathrm{~K}$ and $1123 \mathrm{~K}$, the presented data were calculated from the measured values.

\section{RESULTS AND DISCUSSION}

Figure 1 shows the density of the Sb-Sn-Zn alloys for constant $X_{\mathrm{Sn}} / X_{\mathrm{Sb}}$ ratio of $1,3,4$, and 9 with addition of $0.05,0.1,0.2,0.5,0.7$ mole fraction of $\mathrm{Zn}$. The presented data for the densities of pure $\mathrm{Zn}$ and the Sb-Sn alloys are taken from Ref. 24. As can be observed from this figure, the densities of the ternary alloys are between the density values of the $\mathrm{Sb}$-Sn alloys and pure $\mathrm{Zn} .{ }^{24} \mathrm{We}$ observed the same trend for all the $X_{\mathrm{Sn}} / X_{\mathrm{Sb}}$ ratios: with increasing $\mathrm{Zn}$ addition in the ternary Sb-Sn-Zn alloys, the density decreased. As can be seen from the isotherm of density at temperature of $923 \mathrm{~K}$ (Fig. 2), the composition dependence of the density is not linear, as in the case of the activity of $\mathrm{Zn}$ in $\mathrm{Sb}-\mathrm{Sn}-\mathrm{Zn}$ alloys. $^{23}$ The density data for the binary alloys are taken from Ref. 25 for Sb-Zn, Ref. 24 for Sb-Sn, and Ref. 26 for Sn-Zn. The molar volumes $V_{\mathrm{m}}$ $\left(\mathrm{m}^{3} \mathrm{~mol}^{-1}\right)$ of the $\mathrm{Sb}-\mathrm{Sn}-\mathrm{Zn}$ system at $923 \mathrm{~K}$ are presented in Fig. 3. The calculations of $V_{\mathrm{m}}$ were carried out using the same equation as in Ref. 24 . The observed ternary alloys showed positive deviation from the ideal molar volume. A similar effect was observed for the activity of Zn ternary alloys: ${ }^{22}$ over the whole range, there were positive deviations. However, for the alloys with $X_{\mathrm{Sn}} / X_{\mathrm{Sb}}$ ratio of 1 , the variations were very small and increased with increasing Sn content in the alloy.

Figure 4 presents the surface tension of the Sb-Sn-Zn alloys for constant $X_{\mathrm{Sn}} / X_{\mathrm{Sb}}$ ratio of $1,3,4$, and 9 with $\mathrm{Zn}$ addition. The values of the surface tension are between the values for the $\mathrm{Sn}-\mathrm{Sb}$ alloys and pure $\mathrm{Zn} .{ }^{24}$ With increasing $\mathrm{Zn}$ content in the ternary Sb-Sn-Zn alloys, the surface tension increased. Figure 5 illustrates the isotherm of the surface tension at temperature of $923 \mathrm{~K}$; it can be seen that the surface tension exhibits a nonlinear

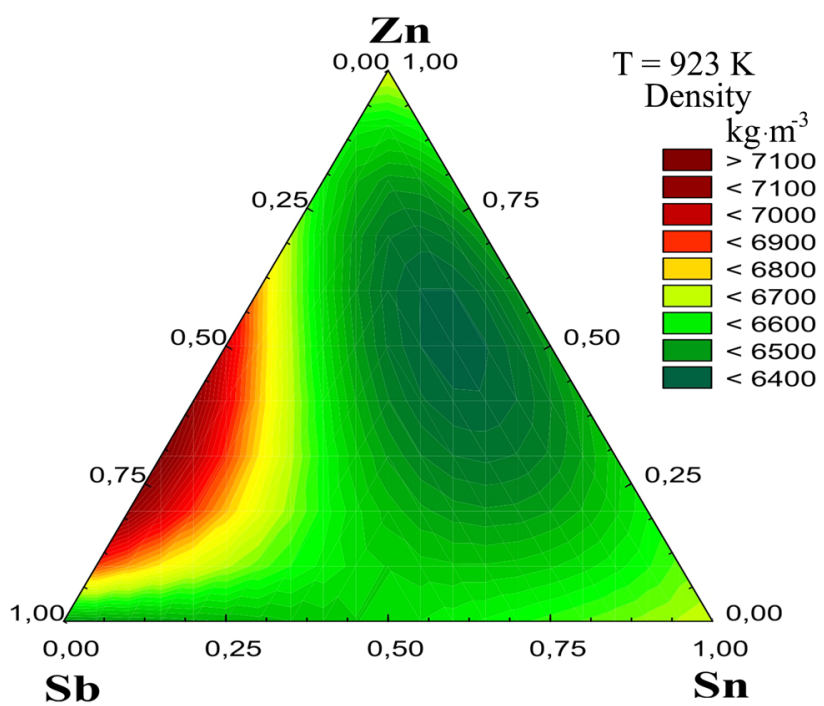

Fig. 2. Isotherm of density of Sb-Sn-Zn alloys at temperature of $923 \mathrm{~K}$.

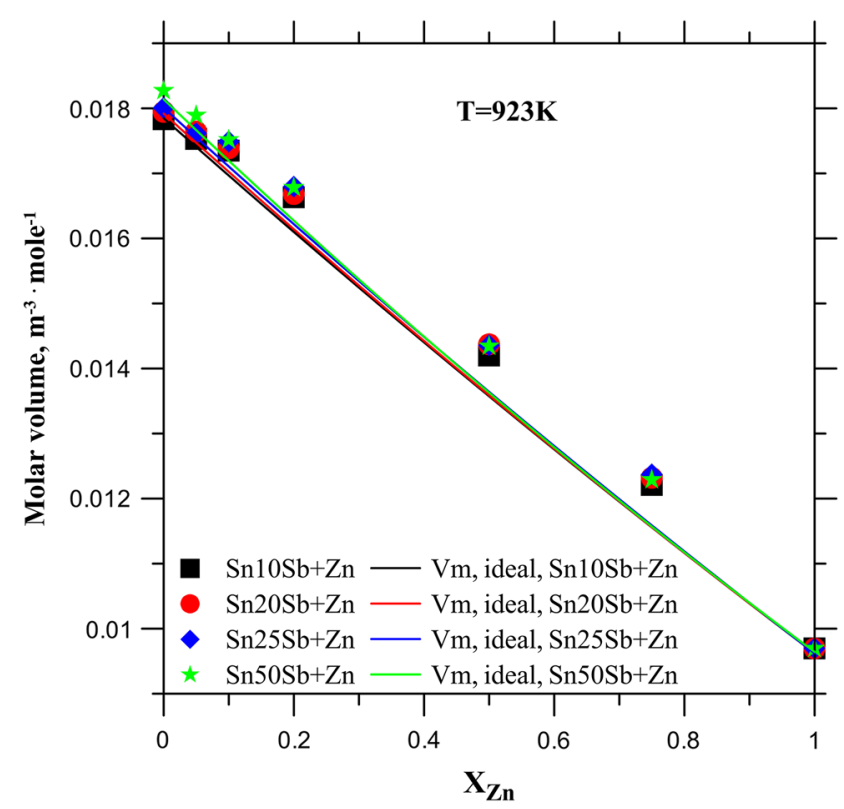

Fig. 3. Molar volumes of the Sb-Sn-Zn system at $923 \mathrm{~K}$.

dependence on the concentration, as for the density. For the prepared isotherm, the data for the binary systems were taken from Ref. 24 for Sb-Sn, Ref. 27 for Sb-Zn, and Ref. 26 for Sn-Zn.

Linear equations for the temperature dependence of the density (Table I) and surface tension (Table II) were determined using the least-squares method, and the coefficients $A$ and $B$ and the errors of these coefficients were calculated. In addition, values were calculated for temperature of $923 \mathrm{~K}$. An 

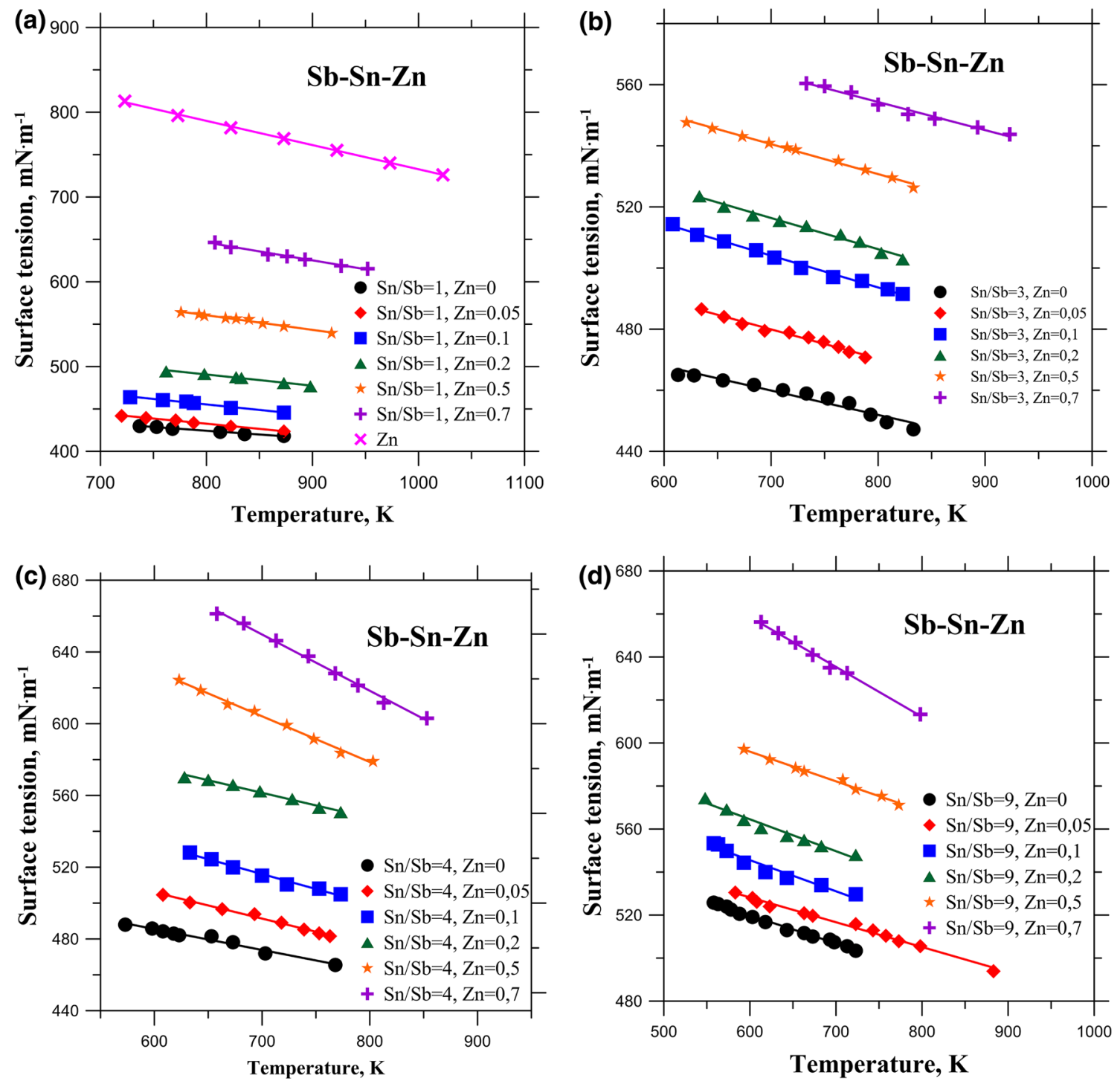

Fig. 4. Surface tension of Sb-Sn-Zn alloys for constant $X_{\mathrm{Sn}} / X_{\mathrm{Sb}}$ ratio of (a) 1, (b) 3, (c) 4, and (d) 9 with Zn addition.

Arrhenius equation describes the viscosity with a designated coefficient $A$ and activation energy $E$. The viscosity values calculated for temperature of $923 \mathrm{~K}$ are summarized in Table III.

The experimentally obtained values of viscosity for the Sb-Sn-Zn alloys are shown in Fig. 6. The viscosity values obtained for the ternary alloys are between the values for pure $\mathrm{Zn}$ and the binary Sb-Sn alloys. ${ }^{24}$ Figure 7 shows the isotherm of viscosity at temperature of $923 \mathrm{~K}$, and Fig. 8 presents a three-dimensional (3D) projection of the viscosity at temperature of $1123 \mathrm{~K}$, which better shows the minima and maxima of the viscosity values of the Sb-Sn-Zn system. These areas are associated with short-range ordering of the ternary $\mathrm{SnZnSb}_{2}$ phase. The viscosity data for the binary alloys were taken from Refs. 28 and 29 for Sb-Zn, Ref. 24 for Sb-Sn, and Refs. 30 and 31 for Sn-Zn.

The results of the experiments were compared with Butler's ${ }^{32}$ model (for surface tension), and with the Moelwyn-Hughes, ${ }^{33}$ Sichen-Boygen-Seetharaman, ${ }^{34}$ Seetharaman-Sichen, ${ }^{35}$ Kozlov-RomanovPetrov, ${ }^{36}$ and Kaptay ${ }^{37}$ models (for viscosity) for the two temperatures (923 K and $1123 \mathrm{~K}$ ). 
The Butler model, ${ }^{32}$ whose theoretical foundations are discussed in Ref. 23, was used for modeling the surface tension. Figures 9, 10, 11, and 12 show the values calculated using the Butler model together with the experimental data for the surface tension for the two temperatures of $923 \mathrm{~K}$ and $1123 \mathrm{~K}$ for $X_{\mathrm{Sn}} / X_{\mathrm{Sb}}$ ratio of $9,4,3$, and 1 with $\mathrm{Zn}$ addition. For the modeling of the surface tension, the density and surface tension of

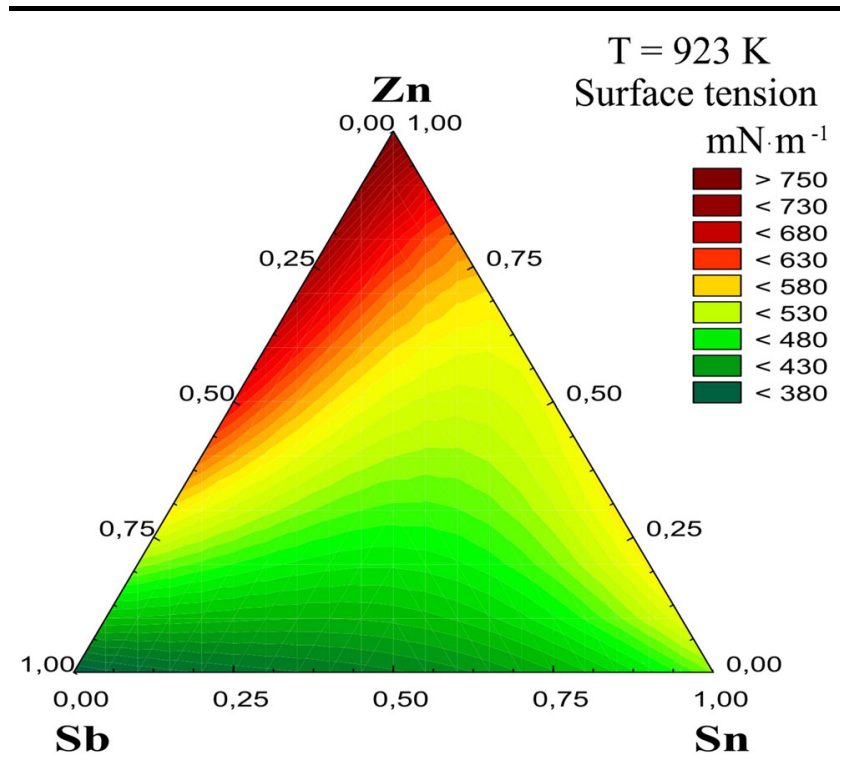

Fig. 5. Isotherm of surface tension of Sb-Sn-Zn alloys at temperature of $923 \mathrm{~K}$. the pure metals determined experimentally in Ref. 24 were used. The optimized thermodynamic parameters for the binary systems used in the model were derived from the European Cooperation in Science and Technology COST 531 database. ${ }^{38}$ There was good agreement between the values obtained from the Butler model and the experimental surface tension data for all the alloys with given $X_{\mathrm{Sn}} / X_{\mathrm{Sb}}$ ratio, although the compatibility seemed to be better at temperature of $923 \mathrm{~K}$ than $1123 \mathrm{~K}$. For the alloys with $X_{\mathrm{Sn}} / X_{\mathrm{Sb}}$ ratio of 1 at temperature of $923 \mathrm{~K}$ and $1123 \mathrm{~K}$, the effect was almost identical.

Isotherms for viscosity were calculated for the Sb-Sn-Zn alloys using the Moelwyn-Hughes, ${ }^{33}$ Sichen-Boygen-Seetharaman, ${ }^{34}$ SeetharamanSichen, ${ }^{35}$ Kozlov-Romanov-Petrov, ${ }^{36}$ and Kaptay ${ }^{37}$ models and are presented in Figs. 13, 14, 15, and 16. The model was discussed in Ref. 23 . The calculation results were compared with their experimental data. Calculations were performed for the Sb-Sn-Zn alloys at constant $X_{\mathrm{Sn}} / X_{\mathrm{Sb}}$ ratio of $9,4,3$, and 1 and variable $\mathrm{Zn}$ content at temperatures of $923 \mathrm{~K}$ and $1123 \mathrm{~K}$. The values of the viscosity, density, and surface tension of the pure metals used in the models were determined experimentally in Ref. 24 . The thermodynamic properties used in the model come from the COST 531 database. ${ }^{38}$ None of the proposed models describes the viscosity values obtained in the experiment in an optimum way. The best compliance between the experimental viscosity data and the modeled values was obtained from

Table I. Density of Sb-Sn-Zn alloys

\begin{tabular}{|c|c|c|c|c|c|c|c|c|}
\hline \multicolumn{3}{|c|}{ Chemical Composition } & \multicolumn{6}{|c|}{$\rho=A+B T\left(\mathrm{~kg} \mathrm{~m}^{-3}\right)$} \\
\hline $\boldsymbol{X}_{\mathbf{S b}}$ & $\boldsymbol{X}_{\mathbf{S n}}$ & $\boldsymbol{X}_{\mathbf{Z n}}$ & $\boldsymbol{A}$ & $\delta \boldsymbol{A}$ & $\boldsymbol{B}$ & $\delta B$ & $\rho(923 \mathrm{~K})$ & $\delta \rho$ \\
\hline 0.095 & 0.855 & 0.05 & 7194.9 & 58.2 & -0.606 & 0.014 & 6635.6 & 58.2 \\
\hline 0.09 & 0.81 & 0.1 & 7261.6 & 5.6 & -0.772 & 0.009 & 6549.0 & 33.4 \\
\hline 0.08 & 0.72 & 0.2 & 7218.7 & 10.2 & -0.769 & 0.011 & 6508.9 & 60.4 \\
\hline 0.05 & 0.45 & 0.5 & 7150.3 & 17.1 & -0.714 & 0.011 & 6491.3 & 112.5 \\
\hline 0.03 & 0.27 & 0.7 & 7107.6 & 10.8 & -0.711 & 0.008 & 6451.3 & 43.9 \\
\hline 0.19 & 0.76 & 0.05 & 7164.5 & 4.9 & -0.602 & 0.009 & 6608.9 & 29.6 \\
\hline 0.18 & 0.72 & 0.1 & 7203.5 & 25.1 & -0.706 & 0.029 & 6551.9 & 125.4 \\
\hline 0.16 & 0.64 & 0.2 & 7242.9 & 12.3 & -0.801 & 0.014 & 6503.6 & 61.4 \\
\hline 0.1 & 0.4 & 0.5 & 7321.2 & 8.9 & -0.973 & 0.011 & 6423.1 & 53.4 \\
\hline 0.06 & 0.24 & 0.7 & 7257.5 & 10.9 & -0.930 & 0.012 & 6399.1 & 43.9 \\
\hline 0.2375 & 0.7125 & 0.05 & 7186.4 & 9.4 & -0.606 & 0.013 & 6627.0 & 65.3 \\
\hline 0.225 & 0.65 & 0.1 & 7128.5 & 20.2 & -0.659 & 0.021 & 6520.2 & 74.9 \\
\hline 0.2 & 0.6 & 0.2 & 7154.7 & 25.2 & -0.744 & 0.024 & 6467.9 & 161.7 \\
\hline 0.125 & 0.375 & 0.5 & 7122.6 & 9.1 & -0.743 & 0.011 & 6436.8 & 176.8 \\
\hline 0.075 & 0.225 & 0.7 & 7150.3 & 35.6 & -0.840 & 0.026 & 6374.9 & 72.1 \\
\hline 0.475 & 0.475 & 0.05 & 7056.3 & 19.8 & -0.532 & 0.016 & 6565.3 & 22.9 \\
\hline 0.45 & 0.45 & 0.1 & 7051.4 & 19.1 & -0.544 & 0.019 & 6549.3 & 29.9 \\
\hline 0.4 & 0.4 & 0.2 & 7124.5 & 13.9 & -0.666 & 0.015 & 6509.6 & 13.4 \\
\hline 0.25 & 0.25 & 0.5 & 7148.0 & 21.4 & -0.735 & 0.011 & 6469.6 & 71.8 \\
\hline 0.15 & 0.15 & 0.7 & 7141.5 & 11.1 & -0.767 & 0.01 & 6433.6 & 10.3 \\
\hline
\end{tabular}


Table II. Surface tension of Sb-Sn-Zn alloys

\begin{tabular}{|c|c|c|c|c|c|c|c|c|}
\hline \multicolumn{3}{|c|}{ Chemical Composition } & \multicolumn{6}{|c|}{$\sigma=A+B T\left(\mathrm{mN} \mathrm{m}^{-1}\right)$} \\
\hline $\boldsymbol{X}_{\mathbf{S b}}$ & $\boldsymbol{X}_{\text {Sn }}$ & $\boldsymbol{X}_{\mathbf{Z n}}$ & $\boldsymbol{A}$ & $\delta \boldsymbol{A}$ & $\boldsymbol{B}$ & $\delta B$ & $\sigma(923 \mathrm{~K})$ & $\delta \sigma$ \\
\hline 0.095 & 0.855 & 0.05 & 597.5 & 1.2 & -0.115 & 0.001 & 491.4 & 11.5 \\
\hline 0.09 & 0.81 & 0.1 & 632.4 & 4.8 & -0.145 & 0.006 & 498.6 & 18.9 \\
\hline 0.08 & 0.72 & 0.2 & 653.4 & 2.6 & -0.148 & 0.004 & 516.8 & 15.9 \\
\hline 0.05 & 0.45 & 0.5 & 678.7 & 1.0 & -0.138 & 0.001 & 551.3 & 5.8 \\
\hline 0.03 & 0.27 & 0.7 & 797.8 & 1.1 & -0.232 & 0.001 & 583.7 & 5.6 \\
\hline 0.19 & 0.76 & 0.05 & 593.9 & 0.6 & -0.146 & 0.001 & 459.1 & 3.7 \\
\hline 0.18 & 0.72 & 0.1 & 632.5 & 1.2 & -0.166 & 0.003 & 479.3 & 7.4 \\
\hline 0.16 & 0.64 & 0.2 & 659.8 & 0.8 & -0.140 & 0.001 & 530.6 & 3.8 \\
\hline 0.1 & 0.4 & 0.5 & 782.6 & 1.2 & -0.255 & 0.002 & 547.2 & 9.7 \\
\hline 0.06 & 0.24 & 0.7 & 869.3 & 2.4 & -0.313 & 0.005 & 580.4 & 14.3 \\
\hline 0.2375 & 0.7125 & 0.05 & 546.7 & 3.9 & -0.095 & 0.005 & 459.01 & 3.8 \\
\hline 0.225 & 0.65 & 0.1 & 577 & 3.5 & -0.104 & 0.003 & 481.00 & 3.5 \\
\hline 0.2 & 0.6 & 0.2 & 587.8 & 5.9 & -0.102 & 0.008 & 493.65 & 8.9 \\
\hline 0.125 & 0.375 & 0.5 & 609.2 & 2.9 & -0.098 & 0.002 & 518.74 & 2.9 \\
\hline 0.075 & 0.225 & 0.7 & 627.9 & 4.9 & -0.092 & 0.007 & 542.98 & 4.9 \\
\hline 0.475 & 0.475 & 0.05 & 529.9 & 0.9 & -0.121 & 0.001 & 418.2 & 1.9 \\
\hline 0.45 & 0.45 & 0.1 & 558.8 & 2.6 & -0.129 & 0.003 & 439.7 & 2.6 \\
\hline 0.4 & 0.4 & 0.2 & 596.3 & 2.8 & -0.132 & 0.004 & 474.5 & 2.8 \\
\hline 0.25 & 0.25 & 0.5 & 698.4 & 8.0 & -0.172 & 0.009 & 539.6 & 8.0 \\
\hline 0.15 & 0.15 & 0.7 & 814.9 & 1.9 & -0.211 & 0.002 & 620.1 & 9.7 \\
\hline
\end{tabular}

Table III. Viscosity of Sb-Sn-Zn alloys

\begin{tabular}{|c|c|c|c|c|c|c|c|c|}
\hline \multicolumn{3}{|c|}{ Chemical Composition } & \multicolumn{6}{|c|}{$\eta=A^{\prime} \mathrm{e}^{E / R T}(\mathbf{m P a} \mathbf{s})$} \\
\hline $\boldsymbol{X}_{\mathbf{S b}}$ & $\boldsymbol{X}_{\mathbf{S n}}$ & $\boldsymbol{X}_{\mathbf{Z n}}$ & $\boldsymbol{A}$ & $\delta \boldsymbol{A}$ & $\boldsymbol{E}$ & $\delta \boldsymbol{E}$ & $\eta(\mathbf{9 2 3} \mathbf{K})$ & $\delta \eta$ \\
\hline 0.095 & 0.855 & 0.05 & 0.329 & 0.010 & 9304.2 & 50.2 & 1.106 & 0.011 \\
\hline 0.09 & 0.81 & 0.1 & 0.245 & 0.009 & $11,482.5$ & 73.1 & 1.094 & 0.009 \\
\hline 0.08 & 0.72 & 0.2 & 0.261 & 0.005 & $11,656.2$ & 49.3 & 1.192 & 0.032 \\
\hline 0.05 & 0.45 & 0.5 & 0.339 & 0.007 & $11,237.2$ & 22.9 & 1.466 & 0.040 \\
\hline 0.03 & 0.27 & 0.7 & 0.326 & 0.006 & $12,306.4$ & 48.7 & 1.621 & 0.018 \\
\hline 0.19 & 0.76 & 0.05 & 0.248 & 0.005 & $11,086.7$ & 30.7 & 1.052 & 0.015 \\
\hline 0.18 & 0.72 & 0.1 & 0.301 & 0.003 & $10,552.1$ & 22.8 & 1.191 & 0.019 \\
\hline 0.16 & 0.64 & 0.2 & 0.321 & 0.001 & $10,633.6$ & 19.3 & 1.283 & 0.017 \\
\hline 0.1 & 0.4 & 0.5 & 0.298 & 0.039 & $11,646.3$ & 146.7 & 1.359 & 0.069 \\
\hline 0.06 & 0.24 & 0.7 & 0.292 & 0.029 & $12,747.9$ & 105.4 & 1.538 & 0.052 \\
\hline 0.2375 & 0.7125 & 0.05 & 0.305 & 0.001 & 9901.2 & 16.4 & 1.108 & 0.016 \\
\hline 0.225 & 0.65 & 0.1 & 0.433 & 0.019 & 8395.5 & 48.9 & 1.293 & 0.019 \\
\hline 0.2 & 0.6 & 0.2 & 0.549 & 0.018 & 7650.3 & 44.8 & 1.487 & 0.041 \\
\hline 0.125 & 0.375 & 0.5 & 0.696 & 0.031 & 6840.8 & 65.1 & 1.697 & 0.038 \\
\hline 0.075 & 0.225 & 0.7 & 0.890 & 0.008 & 5947.1 & 26.7 & 1.931 & 0.024 \\
\hline 0.475 & 0.475 & 0.05 & 0.292 & 0.001 & $11,052.9$ & 19.6 & 1.233 & 0.013 \\
\hline 0.45 & 0.45 & 0.1 & 0.273 & 0.003 & $11,924.7$ & 55.2 & 1.291 & 0.017 \\
\hline 0.4 & 0.4 & 0.2 & 0.319 & 0.002 & $11,310.9$ & 40.7 & 1.393 & 0.012 \\
\hline 0.25 & 0.25 & 0.5 & 0.293 & 0.001 & $12,757.0$ & 20.1 & 1.545 & 0.015 \\
\hline 0.15 & 0.15 & 0.7 & 0.38 & 0.002 & $12,088.8$ & 46.5 & 1.836 & 0.018 \\
\hline
\end{tabular}



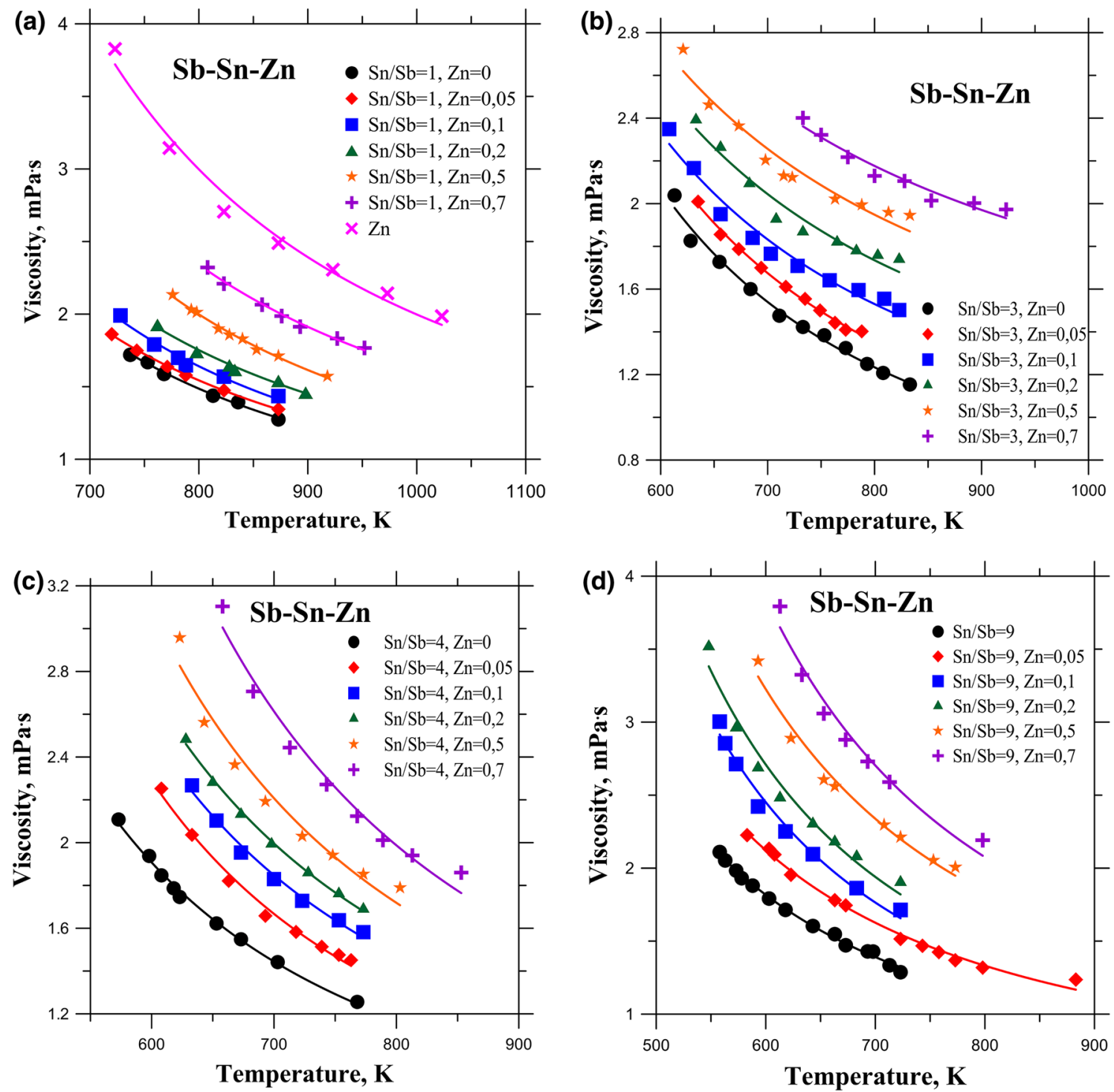

Fig. 6. Viscosity of Sb-Sn-Zn alloys for constant $X_{\mathrm{Sn}} / X_{\mathrm{Sb}}$ ratio of (a) 1, (b) 3, (c) 4, and (d) 9 with Zn addition.

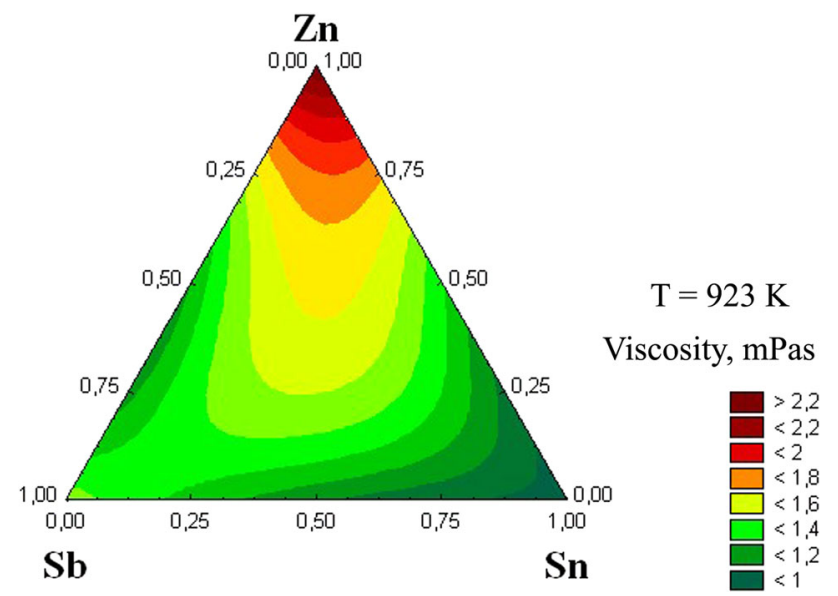

Fig. 7. Isotherm of viscosity of Sb-Sn-Zn alloys at temperature of $923 \mathrm{~K}$.

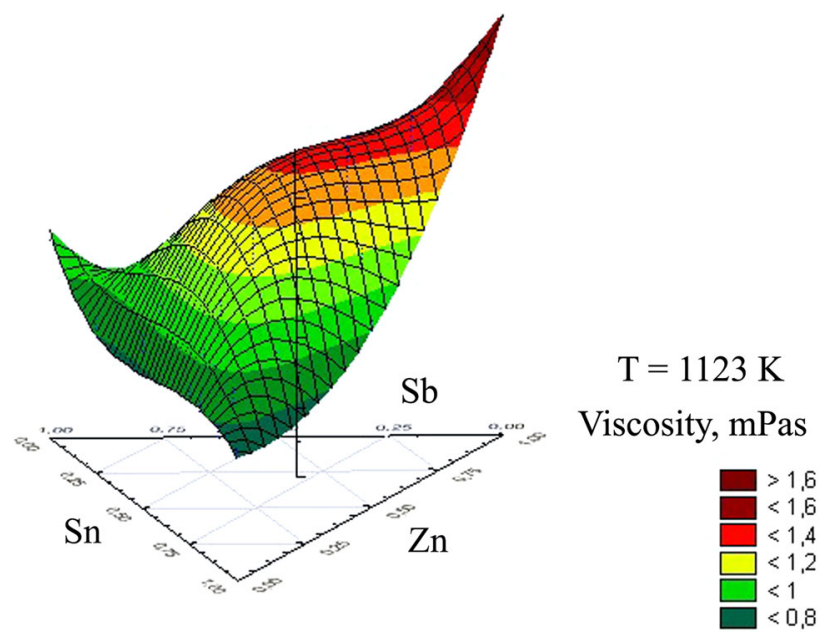

Fig. 8. Three-dimensional projection of viscosity of Sb-Sn-Zn alloys at temperature of $1123 \mathrm{~K}$. 

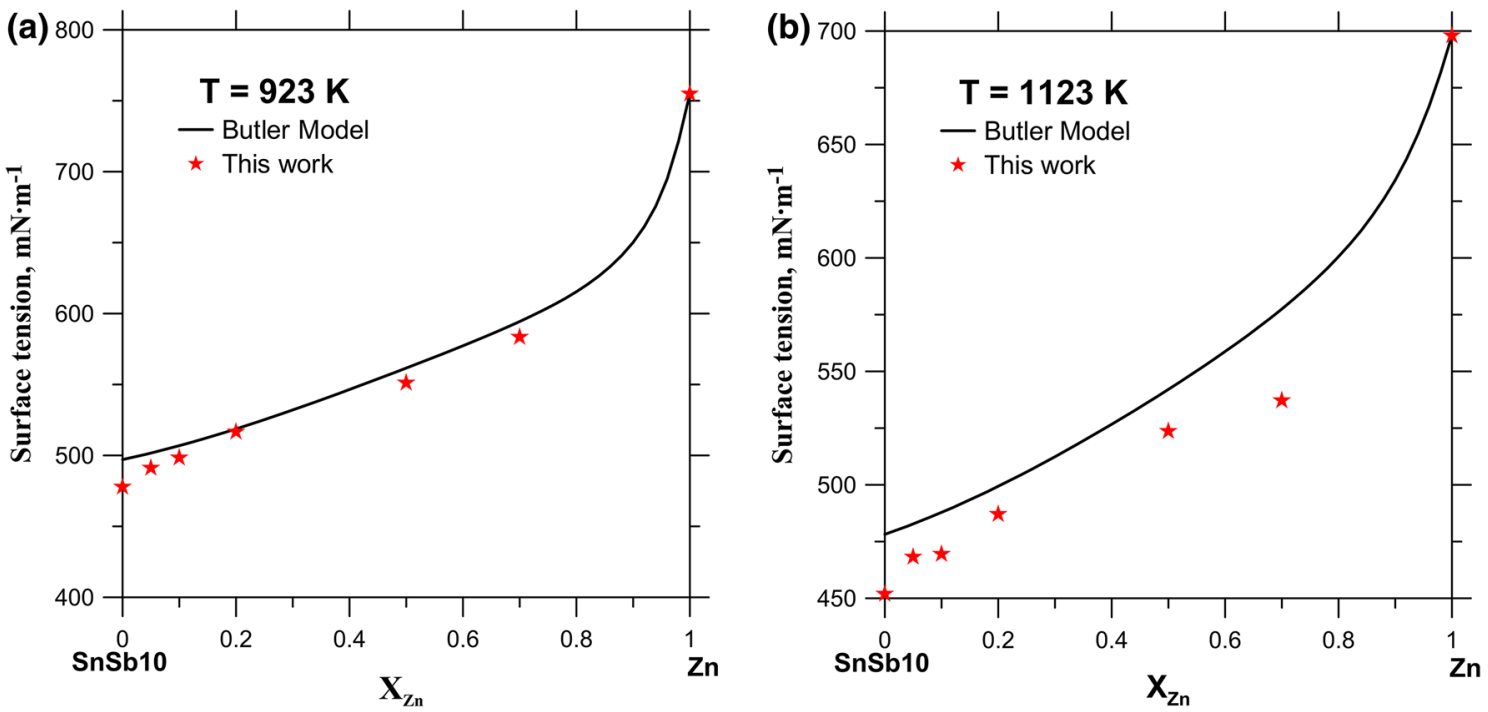

Fig. 9. Experimental surface tension data compared with the Butler model for $\mathrm{Sb}-\mathrm{Sn}$-Zn alloys with $X_{\mathrm{Sn}} / X_{\mathrm{Sb}}$ ratio of 9 at temperature of (a) $923 \mathrm{~K}$ and (b) $1123 \mathrm{~K}$.
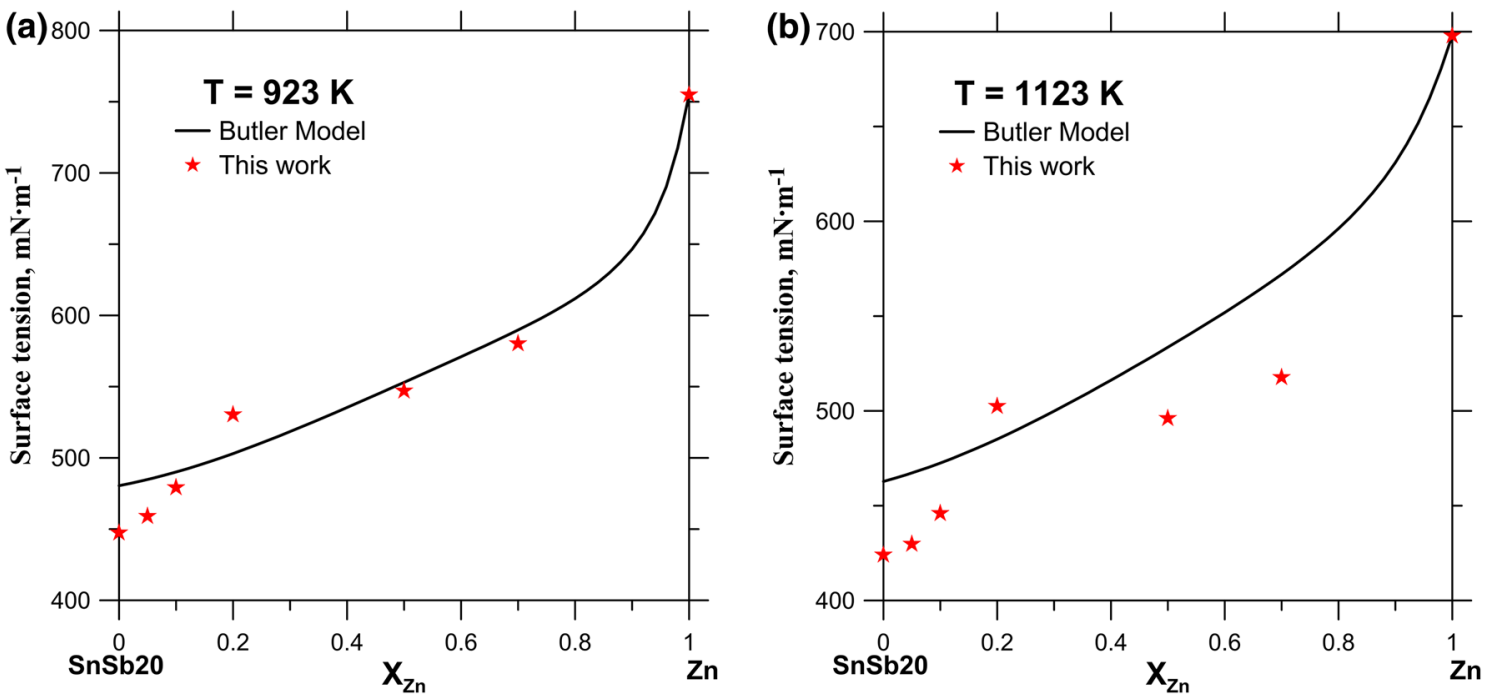

Fig. 10. Experimental surface tension data compared with the Butler model for Sb-Sn-Zn alloys with $X_{\mathrm{Sn}} / X_{\mathrm{Sb}}$ ratio of 4 at temperature of (a) $923 \mathrm{~K}$ and (b) $1123 \mathrm{~K}$.

three models. The first and second are the Kaptay ${ }^{37}$ and Kozlov-Romanov-Petrov ${ }^{36}$ models for $X_{\mathrm{Sn}} / X_{\mathrm{Sb}}$ ratio of 1 at $923 \mathrm{~K}$ and $1123 \mathrm{~K}$. The third is the
Sichen-Boygen-Seetharaman ${ }^{34}$ model for $X_{\mathrm{Sn}} / X_{\mathrm{Sb}}$ ratio of 9 at $1123 \mathrm{~K}$ and for $X_{\mathrm{Sn}} / X_{\mathrm{Sb}}$ ratio of 4 at $923 \mathrm{~K}$ and $1123 \mathrm{~K}$. 

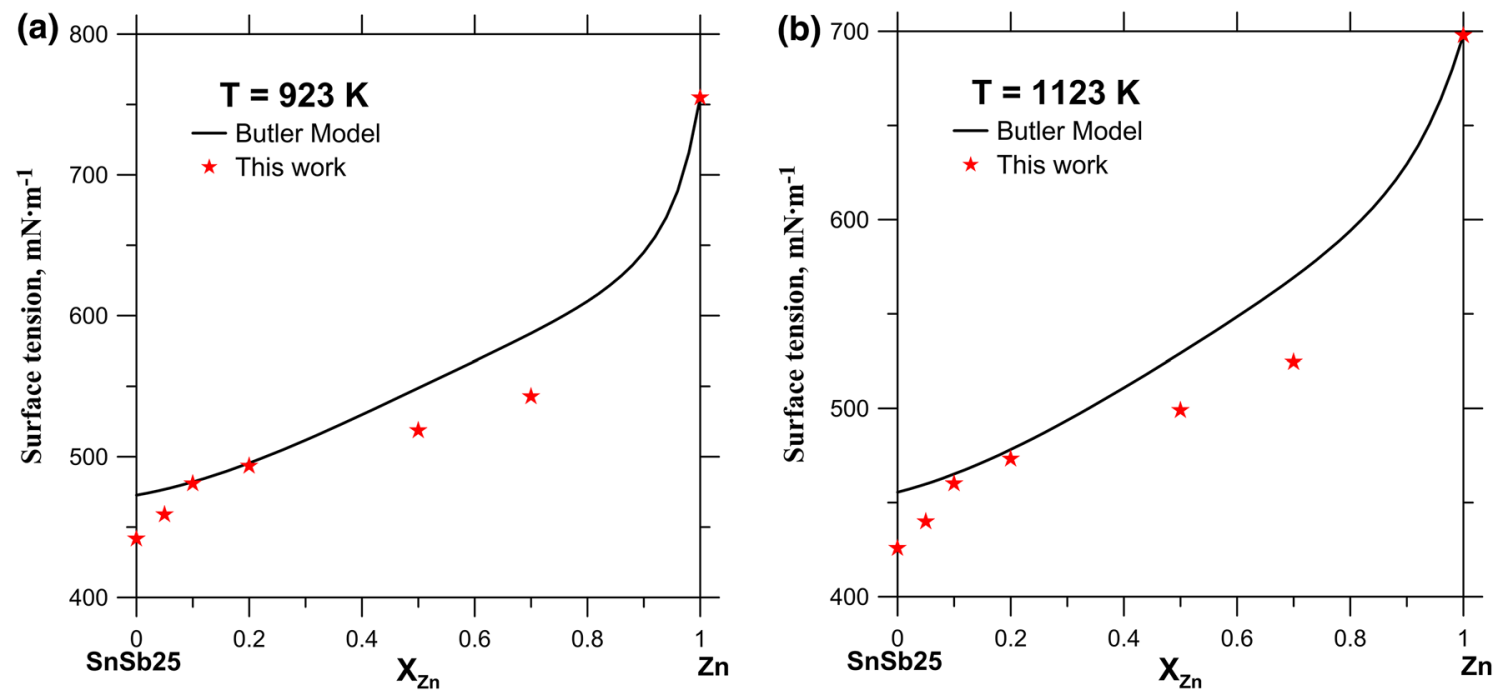

Fig. 11. Experimental surface tension data compared with the Butler model for $\mathrm{Sb}-\mathrm{Sn}-\mathrm{Zn}$ alloys with $X_{\mathrm{Sn}} / X_{\mathrm{Sb}}$ ratio of 3 at temperature of (a) $923 \mathrm{~K}$ and (b) $1123 \mathrm{~K}$.
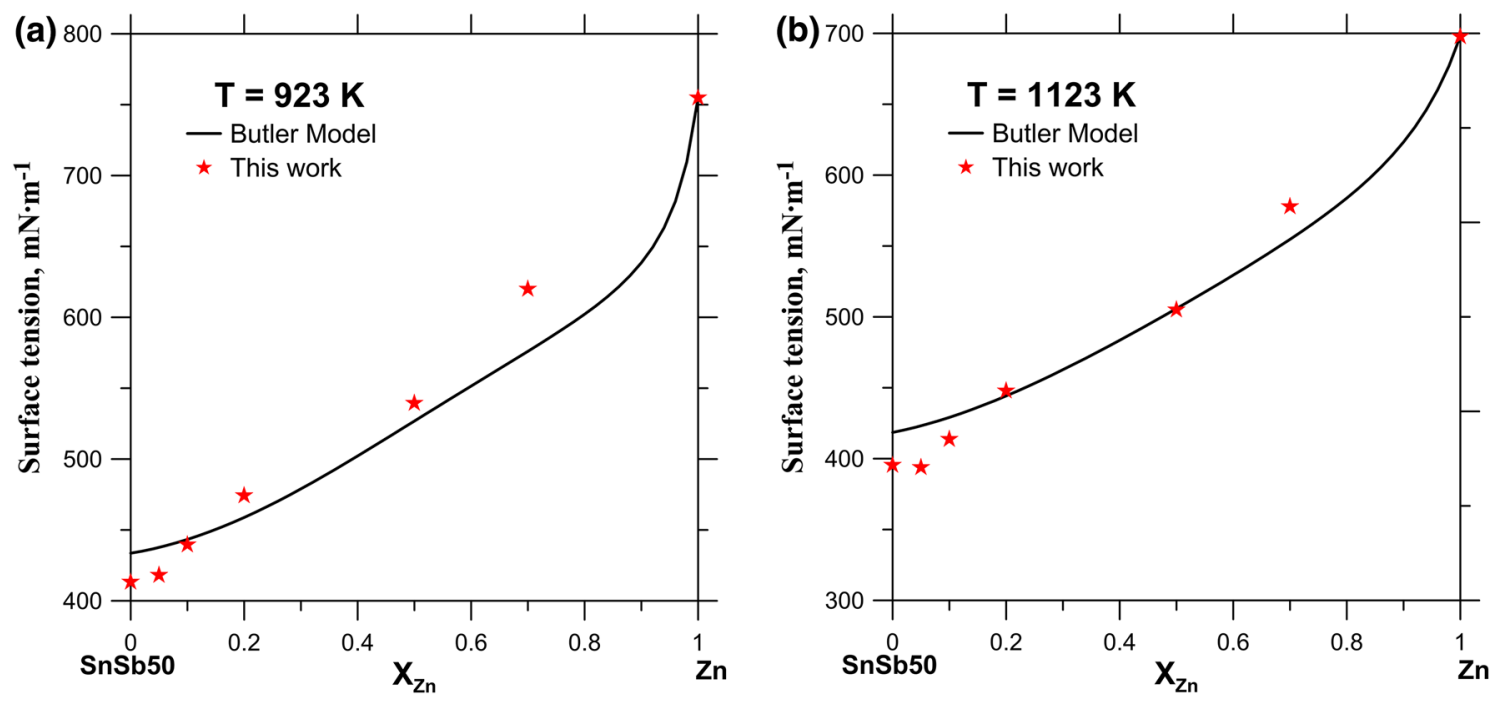

Fig. 12. Experimental surface tension data compared with the Butler model for $\mathrm{Sb}-\mathrm{Sn}-\mathrm{Zn}$ alloys with $X_{\mathrm{Sn}} / X_{\mathrm{Sb}}$ ratio of 1 at temperature of (a) $923 \mathrm{~K}$ and (b) $1123 \mathrm{~K}$.

From the isotherms for viscosity at the temperatures of $923 \mathrm{~K}$ (Fig. 16a) and $1123 \mathrm{~K}$ (Fig. 16b) for constant $X_{\mathrm{Sn}} / X_{\mathrm{Sb}}$ ratio of 1 , one can see that the trend of the viscosity is close to linear with $\mathrm{Zn}$ addition in the Sb-Sn-Zn alloys. However, for fixed $X_{\mathrm{Sn}} / X_{\mathrm{Sb}}$ ratio of 9,3 , and 4 , one sees a different trend 

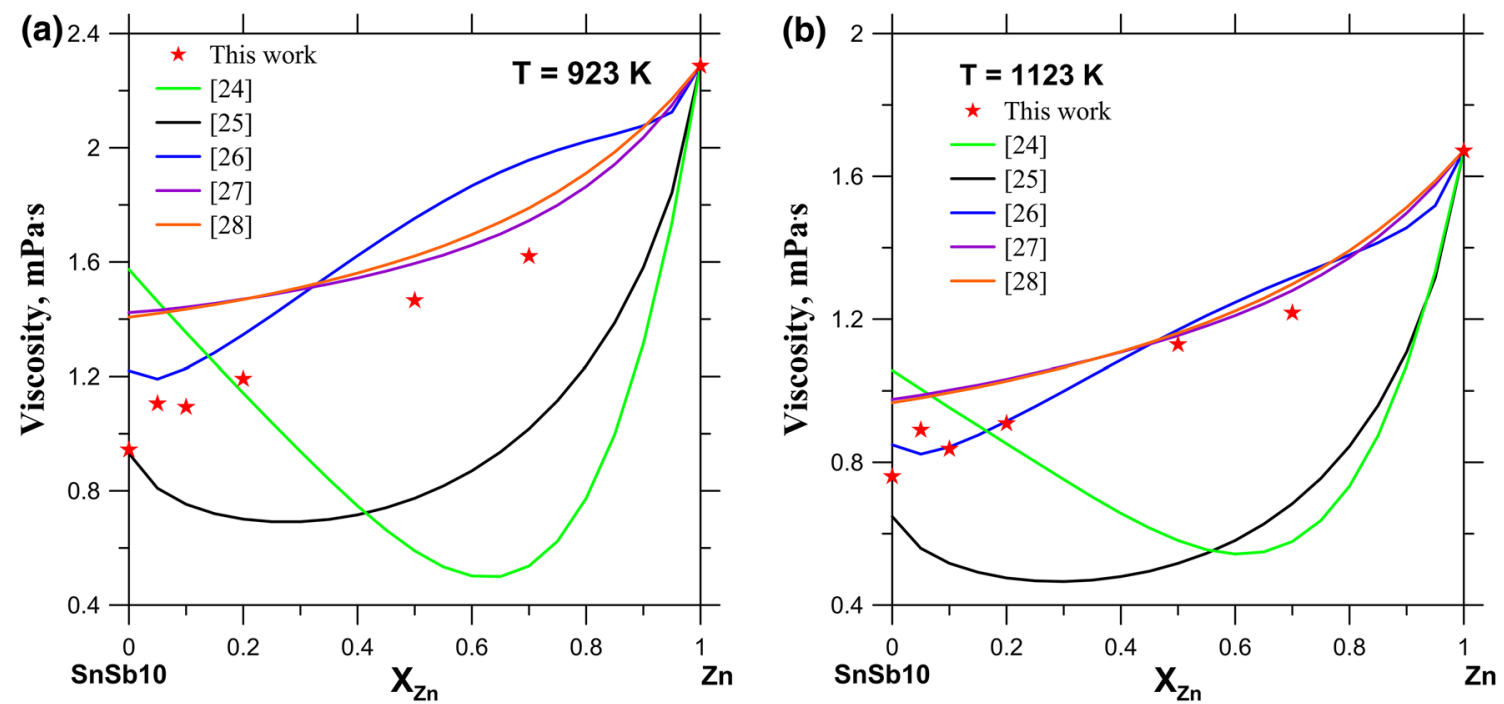

Fig. 13. Experimental viscosity data compared with the viscosity models for $\mathrm{Sb}-\mathrm{Sn}-\mathrm{Zn}$ alloys with $X_{\mathrm{Sn}} / X_{\mathrm{Sb}}$ ratio of 9 at temperature of (a) $923 \mathrm{~K}$ and (b) $1123 \mathrm{~K}$.
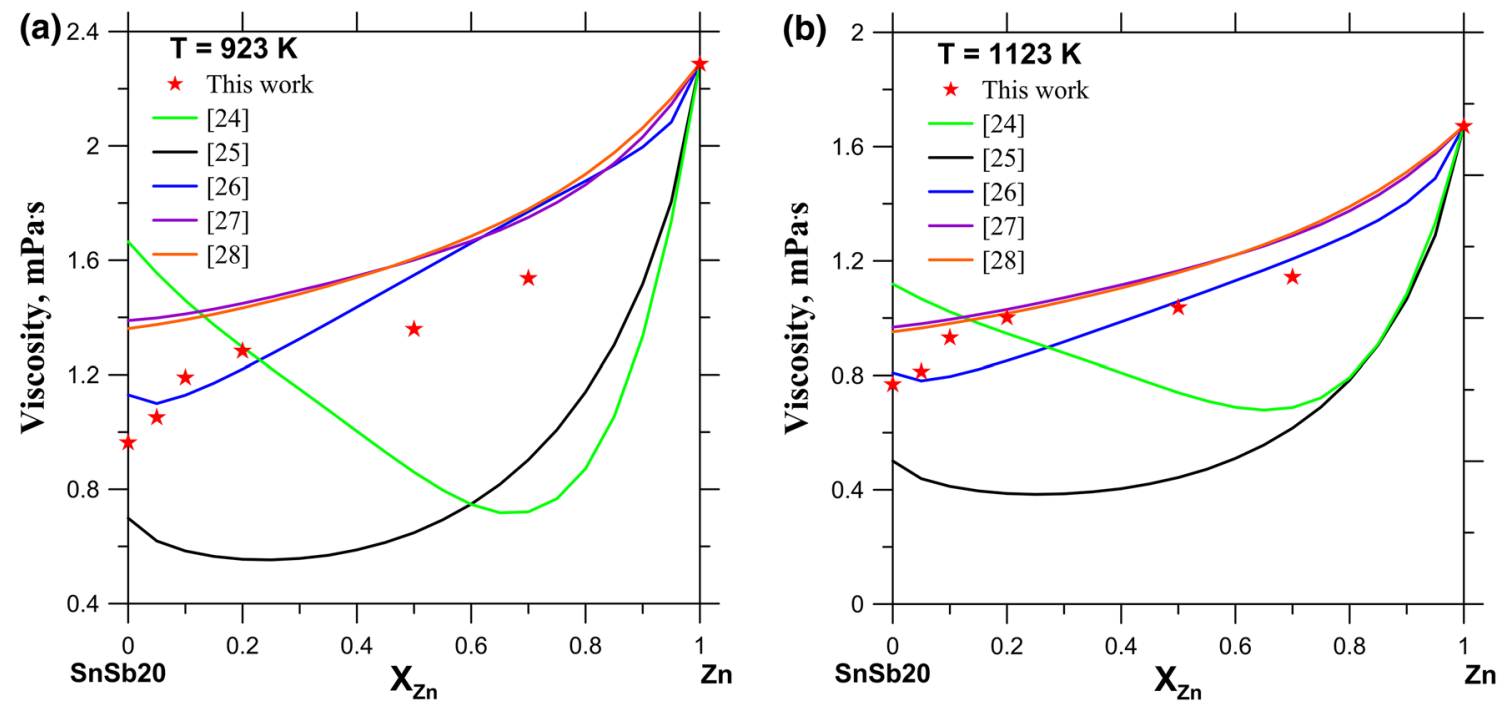

Fig. 14. Experimental viscosity data compared with the viscosity models for $\mathrm{Sb}-\mathrm{Sn}-\mathrm{Zn}$ alloys with $X_{\mathrm{Sn}} / X_{\mathrm{Sb}}$ ratio of 4 at temperature of (a) $923 \mathrm{~K}$ and (b) $1123 \mathrm{~K}$.

in the viscosity. Such trends in viscosity values were also described by Sinha and Miller ${ }^{28}$ and Yao, ${ }^{29}$ who studied the Sb-Zn system. Those authors ${ }^{28,29}$ explained the observed concentration dependence of the viscosity based on short-range ordering in the liquid (maybe associated with the presence of asso- 

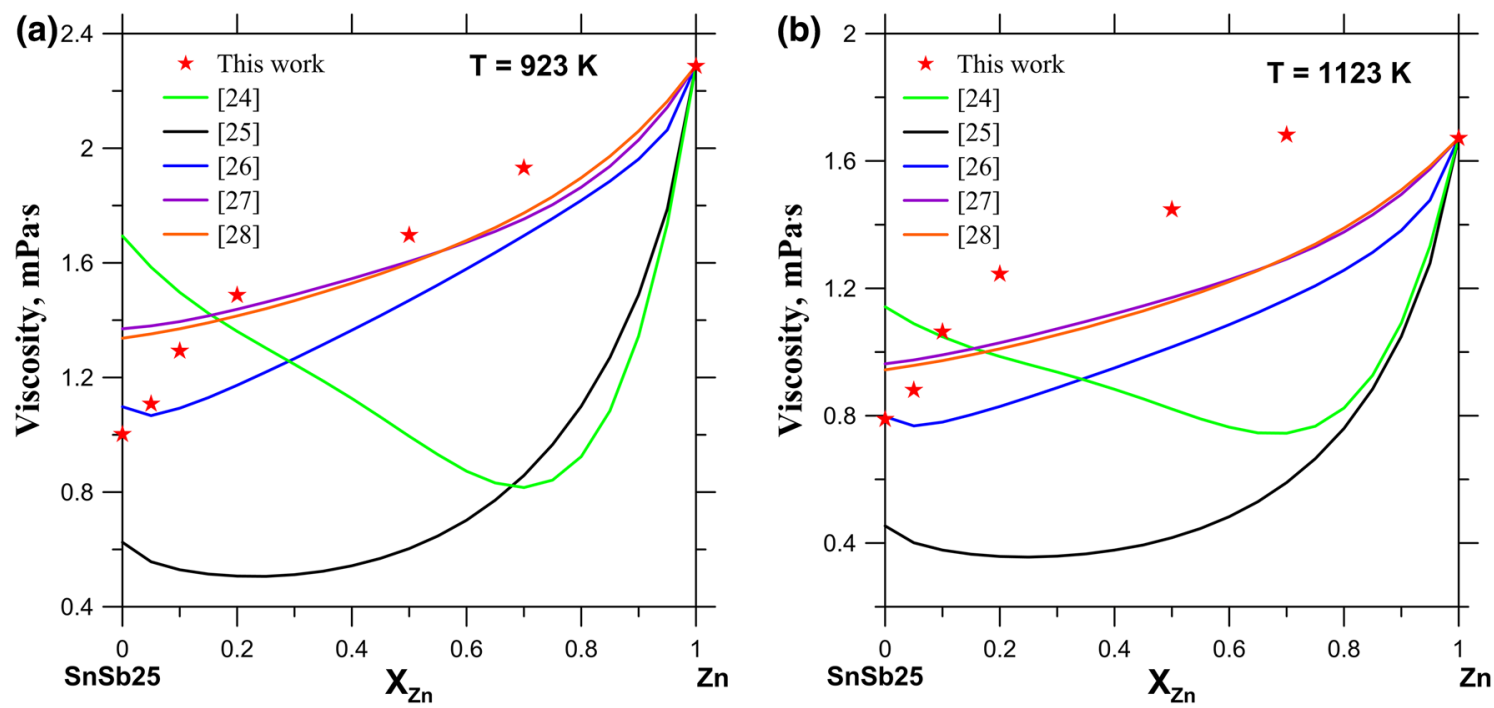

Fig. 15. Experimental viscosity data compared with the viscosity models for $\mathrm{Sb}-\mathrm{Sn}-\mathrm{Zn}$ alloys with $X_{\mathrm{Sn}} / X_{\mathrm{Sb}}$ ratio of 3 at temperature of (a) $923 \mathrm{~K}$ and (b) $1123 \mathrm{~K}$.
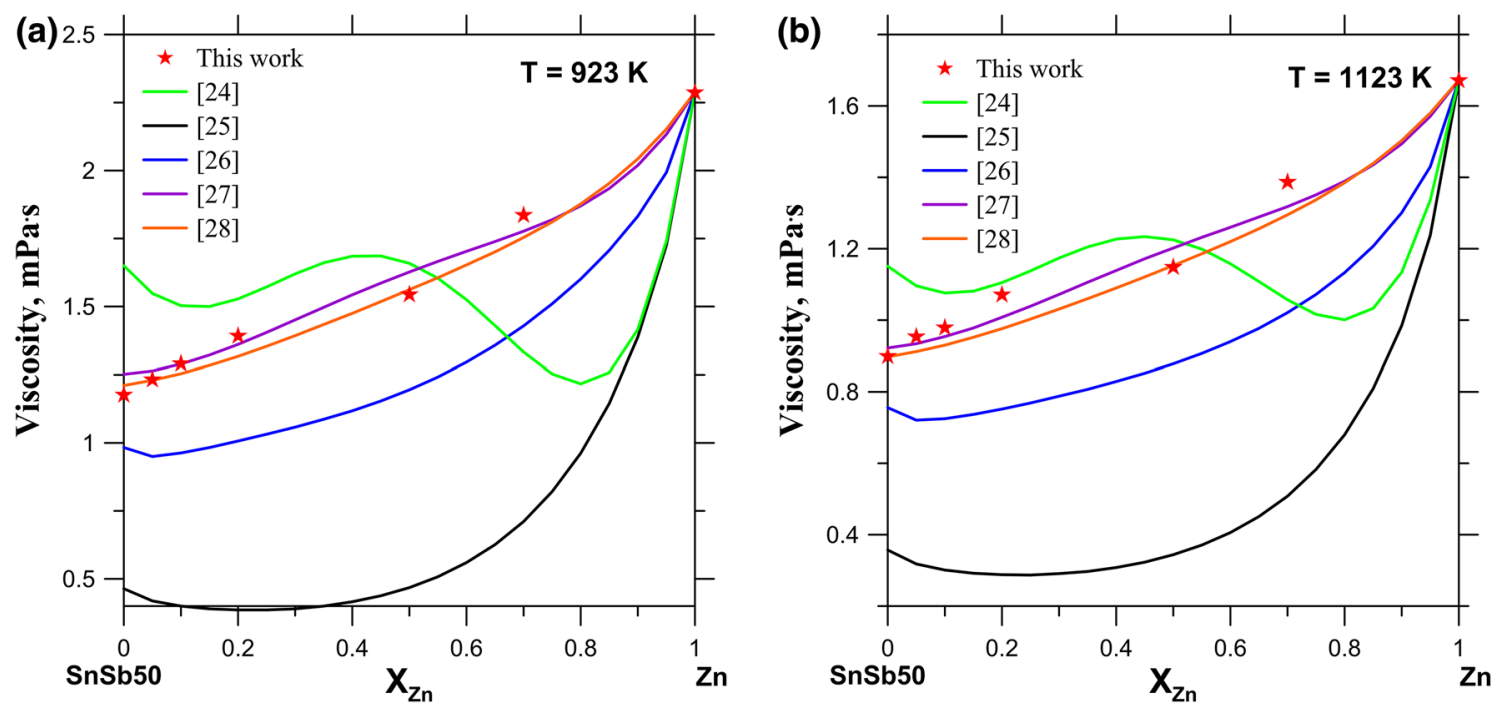

Fig. 16. Experimental viscosity data compared with the viscosity models for $\mathrm{Sb}-\mathrm{Sn}-\mathrm{Zn}$ alloys with $X_{\mathrm{Sn}} / X_{\mathrm{Sb}}$ ratio of 1 at temperature of (a) $923 \mathrm{~K}$ and (b) $1123 \mathrm{~K}$ 
ciates with composition similar to the intermetallic composition), resulting in an increase in the value of the viscosity.

\section{CONCLUSIONS}

The presented experimental results show that the density of all the tested alloys decreased with increasing temperature and with increasing content of zinc and antimony, whereas the surface tension and viscosity of all the alloys decreased with increasing temperature but increased with increasing zinc content. The measured results for the surface tension show good agreement with the Butler model. For viscosity, the Kaptay ${ }^{37}$ and Kozlov-Romanov-Petrov ${ }^{36}$ models are in agreement with the experimental measurements.

Such wide knowledge of the physicochemical properties of these alloys could extend the possible applications of this system, and the presented data could be used for designing new lead-free solder materials.

\section{ACKNOWLEDGEMENTS}

This work was financed by the Ministry of Science and Higher Education of Poland, within the project No. 630/N Kanada/2009 "using a new method for simultaneous measurement of surface tension, density and viscosity for use in soldering materials and new alloys for the automotive industry".

\section{OPEN ACCESS}

This article is distributed under the terms of the Creative Commons Attribution License which permits any use, distribution, and reproduction in any medium, provided the original author(s) and the source are credited. 3

\section{REFERENCES}

1. S.A. Mladenović, L.S. Ivanić, M.M. Rajčić-Vujasinović, S.L. Ivanov, and D.M. Gusković, Hem. Ind. 67, 477-484 (2012).

2. K. Pan, Y. Tyan, D. Preuss, Patent no. 4,774,170 (1988).

3. A. Tenga (Ph.D. thesis, Stockholm, 2010).

4. N. Kang, H.S. Na, S.J. Kim, and C.Y. Kang, J. Alloys Compd. 467, 246 (2009).

5. S. Ganesan and M. Pecht, Lead-Free Electronics (Hoboken, NJ: Wiley, 2006).

6. K. Suganuma and K. Kim, J. Mater. Sci. Mater. Electron. 18, $121(2007)$

7. S. Kim, K. Kim, S. Kim, and K. Suganuma, J. Electron. Mater. 38, 2 (2009).
8. L. Zhang, S. Xue, L. Gao, G. Zeng, Y. Chen, and S. Yu, J. Mater. Sci. Mater. Electron. 21, 1 (2010).

9. P. Fima, T. Gancarz, J. Pstrus, K. Bukat, and J. Sitek, Solder. Surf. Mt. Technol. 24, 71 (2012).

10. M.F. Arenas and V.L. Acoff, J. Electron. Mater. 33, 12 (2004).

11. Z. Moser, P. Fima, K. Bukat, J. Sitek, J. Pstruś, W. Gạsior, M. Kościelski, and T. Gancarz, Solder. Surf. Mt. Technol. 23, 22 (2011)

12. K. Suganuma, Curr. Opin. Solid State Mater. Sci. 5, 55 (2001).

13. K. Seelig and D. Suraski, Lead-Free Soldering Guide (www. aimsolder.com, 2003). Accessed 1 Aug 2014.

14. S. Mhiaoui, F. Sar, and J.G. Gasser, J. Non-Cryst. Solid 353, 3628 (2007).

15. X. Wei, H. Huang, L. Zhou, M. Zhang, and X. Liu, Mater. Lett. 61, 655 (2007).

16. H.T. Lee, M.H. Chen, H.M. Jao, and C.J. Hsu, J. Electron. Mater. 33, 1048 (2004).

17. G.Y. Li, B.L. Chen, X.Q. Shi, S.C.K. Wong, and Z.F. Wang, Thin Solid Films 504, 421 (2006).

18. R. Novakovic, T. Lanata, S. Delsante, and G. Borzone, Mater. Chem. Phys. 137, 458 (2012).

19. V. Sklyarchuk, Y. Plevachuk, I. Kaban, and R. Novakovic, J. Min. Metall. Sect. B 48, B443 (2012).

20. A.Z. Miric and A. Grusd, Solder. Surf. Mt. Technol. 10/1, 19 (1998).

21. V.A. Khudolii, M.I. Golovei, and A.V. Novoselova, Dokl. Chem. 228, 430 (1976).

22. T. Gancarz and W. Gasior, J. Phase Equilib. Diffus. 32, 398 (2011).

23. T. Gancarz, Z. Moser, W. Gạsior, J. Pstruś, and H. Henein, Int. J. Thermophys. 32, 1210 (2011).

24. T. Gancarz, W. Gąsior, and H. Henein, Int. J. Thermophys. 34, 250 (2013).

25. L. Dim, A. Bath, J.G. Gasser, J.L. Bretonnet, and R. Kleim, Phys. Lett. A 84, 375-377 (1981).

26. Z. Moser, W. Gasior, K. Bukat, J. Pstruś, and J. Sitek, Arch. Metall. Mater. 53, 1055 (2008).

27. W. Gasior, Z. Moser, and J. Pstrus, J. Phase Equilib. 24, 504 (2003).

28. A. Sinha and E. Miller, Met. Trans. 1, 1356 (1970).

29. T. Yao, Z. Metallkd. 16, 837 (1956).

30. T. Sato and S. Munakata, Bull. Res. Inst. Min. Dress. Met. 10, 173 (1954).

31. A. Crawley and D. Kiff, Met. Trans. 3, 157 (1972).

32. J.A.V. Butler, Proc. R. Soc. Lond. Ser. A CXXXV, 348-375 (1932)

33. E.A. Moelwyn-Hughes, Physikalische Chemie (Stuttgart, 1970).

34. D. Sichen, J. Bygdén, and S. Seetharaman, Metall. Mater. Trans. B 25, 519 (1994).

35. S. Seetharaman and D. Sichen, Metall. Mater. Trans. B 25, 589 (1994).

36. L.Y. Kozlov, L.M. Romanov, and N.N. Petrov, Izv. Vuzov. Chernaya Metall. 3, 7 (1983).

37. G. Kaptay, Proceedings of MicroCAD 2003, International Conference Section: Metallurgy (Hungary: University of Miskolc, 2003), p. 23.

38. A.T. Dinsdale, A. Watson, A. Kroupa, J. Vrestal, A. Zemanowa, and J. Vizdal, COST 531 Database for the LeadFree Solders (2008). 